УДК 902

ББК 63.4

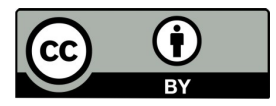

Дата поступления статьи: 29.09.2021

Дата принятия статьи: 28.10.2021

\title{
ПРОБЛЕМАТИКА ИССЛЕДОВАНИЙ ЭПОХИ БРОНЗЫ ЮЖНОГО УРАЛА \\ В РАБОТАХ В.С.ГОРБУНОВА, Ю.А.МОРОЗОВА, Н.Г.РУТТО \\ (К ЮБИЛЕЯМ УЧЕНЫХ)
}

Янина Валерьевна Рафикова

Институт истории, языка и литературы, УФИЦ РАН, Уфа, Россия

E-mail: ziada@bk.ru

Аннотация. Статья посвящена юбилеям известных уфимских исследователей эпохи бронзы В.С. Горбунова, Ю.А. Морозова и Н.Г. Рутто. Охарактеризованы их основные научные достижения, исследованные ими памятники, их публикации, наиболее яркие находки. Отмечен их весомый вклад в археологическую науку. Основными заслугами В.С.Горбунова являются всестороннее освещение данных по приуральской абашевской культуре и обобщение огромного объема материалов эпохи бронзы Волго-Уральского региона, накопленного к началу 90-х гг. ХХ в. Ю.АМорозовым систематизированы и охарактеризованы материалы срубной культуры Бельско-Уральского междуречья, реконструирована хозяйственная деятельность, выявлены направлений культурных связей, уточнены хронология и периодизация срубной культуры Южного Урала. Н.Г. Рутто посвятила свои исследования вопросам взаимосвязей крупных культурно-исторических общностей - срубной и алакульской. Результаты ее работ были систематизированы в монографии «Срубно-алакульские связи на Южном Урале» (2003), где были проанализированы материалы 30 поселений и 78 могильников с проявлениями срубно-алакульского синкретизма, определены зоны наиболее активных контактов, их времени и наиболее вероятных механизмов.

Ключевые слова: эпоха бронзы, Башкирское Приуралье, В.С.Горбунов, Ю.А. Морозов, Н.Г.Рутто, абашевская культура, срубная культура, срубно-алакульские связи

Цитирование. Рафикова Я.В., 2021. Проблематика исследований эпохи бронзы Южного Урала в работах В.С. Горбунова, Ю.А. Морозова, Н.Г.Рутто (к юбилеям ученых) // Уфимский археологический вестник. Т. 21, №2. C. 198-205. DOI: https://doi.org/10.31833/uav/2021.21.2.001

UDC 902

Submitted: 29.09 .2021

LBC 63.4

Accepted: 28.10 .2021

\section{RESEARCH QUESTIONS IN THE STUDIES OF THE SOUTHERN URALS IN THE BRONZE AGE PERIOD CONDUCTED BY V.S. GORBUNOV, Y.A. MOROZOV, N.G.RUTTO (TO THE SCHOLARS' ANNIVERSARIES) \\ Yanina V. Rafikova \\ Institute of History, Language and Literature, UFRC RAS, Ufa, Russia, Ufa, Russia E-mail: ziada@bk.ru}

\begin{abstract}
This article discusses the major works of several Ufa-born researchers (V.S.Gorbunov, Y.A. Morozov and N.G. Rutto), who study the Southern Urals region in the Bronze Age period. V.S. Gorbunov has studied dozens of the Bronze Age settlements and necropolises located in the Cis-Urals region. For example, the famous settlements of Beregovskoye I, Tyubyak, Yumakovskoe I, II, III and Beregovskij, Krasnogorskij III, Novo-Yabalaklinskij, Yumakovskij I, II, Staro-Yabalaklinskij necropolises. The main results of the researcher's work include the detailed description of the history of the Ural Abashevo culture and the comprehensive summary of data related to the Bronze Age assemblages collected in the Volga-Ural region by the early 1990s. Y.A. Morozov has studies a huge series of settlements and burial sited dated back to the Bronze Age period. The sites that have been extensively studied include Chishminskoe, Ismagilovskoe, Abdullovskoe III, Usmanovskoe I and II, Kazangulovskoe, Aitovskoe and Tavlykaevskoe settlements as well as Staro-Yabalaklinskij, Chishmy, and Nikolaevskij necropolises. Besides the Bronze Age sites, the researcher has actively studied a number of Neolithic and Chalcolithic sites, such as the Srednyaya Oka, Kara-Yakupovo, Chishmy, Maksyutovo, Burtyuk and Gumerovo settlements. Y.A. Morozov made a significant contribution to the systematization and characterization of the assemblages of the Srubnaya culture discovered in the Belaya-Ural interfluve region. He reconstructed its features of the economics and cultural relations. The researcher also clarified the chronology and periods of development of the Srubnaya culture in the Southern Urals region. The main results of years-long research by N.G. Rutto could be found in his monograph "Srubnaya-Alakul relations in the Southern Urals". The work discusses the questions of interrelationship between the Srubnaya and Alakul cultural and historical communions. It presents the analysis of assemblages from 30 settlements and 78 necropolises, showing features of both cultures, which allowed researcher to identify the areas of contacts, their longevity and most probable mechanisms.
\end{abstract}


Keywords: Bronze Age, Bashkir Cis-Urals, V.S. Gorbunov, Y.A. Morozov, N.G. Rutto, Abashevo culture, Srubnaya culture, Srubnaya-Alakul cultural relations

Citation. RafikovaY., 2021. Research questions in the studies of the Southern Urals in the Bronze Age period conducted by V.S. Gorbunov, Y.A. Morozov, N.G. Rutto (to the scholars' anniversaries). Ufimskij arkheologicheskiy vestnik [The Ufa Archaeological Herald]. Vol.21, no.2, pp.198-205. (In Russ.). DOI: https://doi.org/10.31833/ uav/2021.21.2.001

\section{Введение}

Основная часть этого номера журнала посвящена эпохе бронзы, в том числе и нашим учителям, старшим коллегам и наставникам, юбилеи которых мы отмечаем в 2021 году. Среди них Юрий Алексеевич Морозов (1941 г.р.), Владимир Степанович Горбунов (1946 г.р.) и Наталья Георгиевна Рутто (1946-2007 гг.), чей вклад в изучение эпохи бронзы Южного Урала очень весом. Начало их исследовательской деятельности пришлось на 70-егг. ХХв., когда в археологии Южного Урала основополагающей была концепция бронзового века, сформулированная К.В.Сальниковым, который с привлечением всех известных на то время археологических материалов разработал проблемы происхождения, хозяйственной деятельности, общественного строя и идеологии носителей абашевской, срубной, андроновской, черкаскульской и курмантауской культур, а также их хронологии и периодизации [Сальников, 1967]. Данные обобщения и выводы были сделаны К.В. Сальниковым на достаточно ограниченных по объему материалах. Перед исследователями «постсальниковского» периода, в передовой отряд которых входили и наши юбиляры, стояли задачи расширения географии археологических памятников, масштабов полевых работ, систематизации накопленных материалов, количество которых в результате их исследований значительно выросло, а также уточнения хронологии и периодизации культур эпохи бронзы Южного Урала.

\section{Владимир Степанович Горбунов}

Обзор научной деятельности каждого юбиляра требует отдельной большой статьи (или даже книги). Ограниченные рамки статьи не позволяют в полной мере осветить всю многогранную деятельность юбиляров, отметим только наиболее весомые и значимые ее результаты.

Владимиром Степановичем Горбуновым полевые исследования проводились в основном на территории Южного Приуралья. За его плечами множество экспедиций, в которых исследованы десятки поселений и могильников эпохи бронзы. Материалы ряда из них стали опорными в решении многих проблем эпохи бронзы Южного Урала. Это многослойные поселения Береговское I, Тюбяк, Юмаковское I, II, III; могильники Береговский, Красногорский III, Ново-Ябалаклинский, Юмаковский I, II, абашевские курганы Старо-Ябалаклинского могильника и т.д.

Результаты исследований В.С.Горбунова изложены более чем в 200 научных статьях и 6 монографиях. Усилия ученого, прежде всего, были направлены на исследование проблем абашевской и срубной КИО, причем, в ракурсе его внимания находились, в первую очередь, археологические памятники лесостепного Приуралья. Благодаря его работам история приуральских абашевцев перестала быть «белым пятном». Впервые в его кандидатской диссертации были рассмотрены вопросы типологии и классификации погребальных памятников, предложена реконструкция абашевских поселков, скорректированы хронологические позиции абашевских памятников Приуралья [Горбунов, 1977а]. Результаты этой работы отражены в монографии «Абашевская культура Южного Приуралья〉 [Горбунов, 1986]. С сожалением приходится констатировать, что с прекращением полевой деятельности В.С.Горбунова остановились и систематические исследования абашевских памятников в Южном Приуралье.

Великолепное знание материалов поселений эпохи бронзы лесостепного Приуралья позволило исследователю подготовить работу, в которой определены основы хозяйственной деятельности и традиции домостроительства носителей различных культур, кроме того, стратиграфические наблюдения и выявление закономерностей в комбинациях взаимовстречаемости керамики разных культур на поселениях послужили данными для уточнения их периодизации и хронологии [Горбунов, 1989].

Одной из актуальнейших задач в бронзоведении Волго-Уралья к началу 90-хгг. ХХ в. являлось обобщение огромного объема материалов, накопленного к этому времени. Это было реализовано в докторской диссертации В.С. Горбунова «Бронзовый век Волго-Уральской лесостепи», которая была издана в том же году в виде монографии [Горбунов, 1992]. До сегодняшнего дня эта работа является единственной, в которой всесторонне охарактеризованы основные археологические культуры эпохи бронзы Волго-Уралья.

Отметим, что на долю далеко не каждого археолога, ведущего многолетние полевые изыскания, выпадает удача исследовать яркие неординарные комплексы, остающиеся в дальнейшем непревзойденными. Владимиру Степановичу в этом плане повезло. Им было открыто погребение 3 кургана 2 Ново-Ябалаклинского могильника, выделяющееся богатством находок и необычностью обряда, где в ногах взрослой женщины была положена девочка-подросток. Уникальный нагрудник-накосник из него по сей день остается самым эффектным и выразительным в серии подобных находок ВолгоУральского и Урало-Казахстанского регионов, несмотря на ее значительное увеличение за последние 30 лет [Горбунов, 1977б]. 


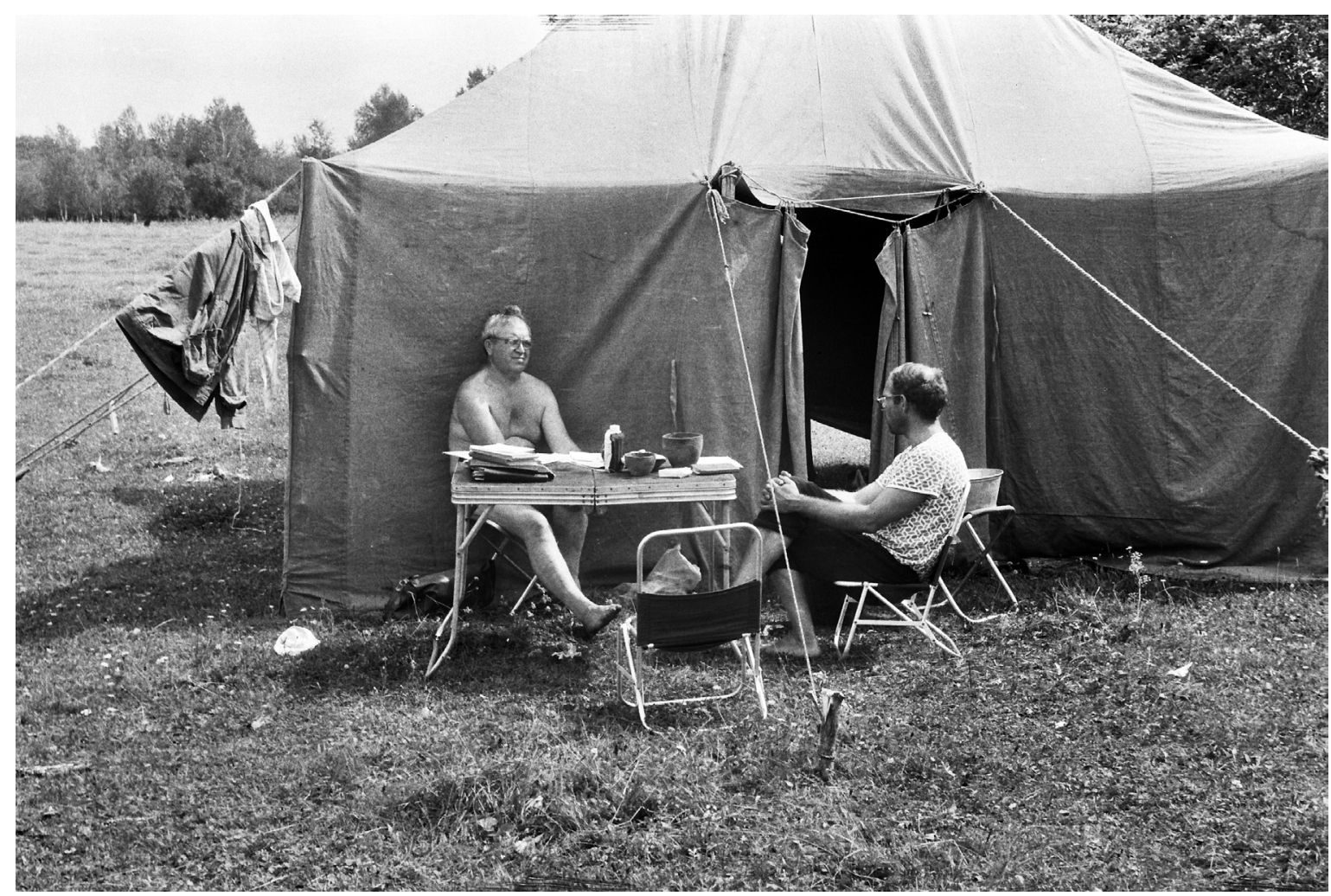

Рис. 1. В.С. Горбунов в полевом лагере в период исследования Ахметовских курганов в Чекмагушевском районе Башкортостана. 1993 год. Фото из архива отдела археологических исследований ИИЯЛ УФИЦ РАН

Fig. 1. V.S. Gorbunov in the camp of expedition, excavating Akhmetovo burial mounds in Chekmagushevsky district of the Republic of Bashkortostan. 1993. Photo from the archive of the Archaeological Research department of the IHLL UFRC RAS

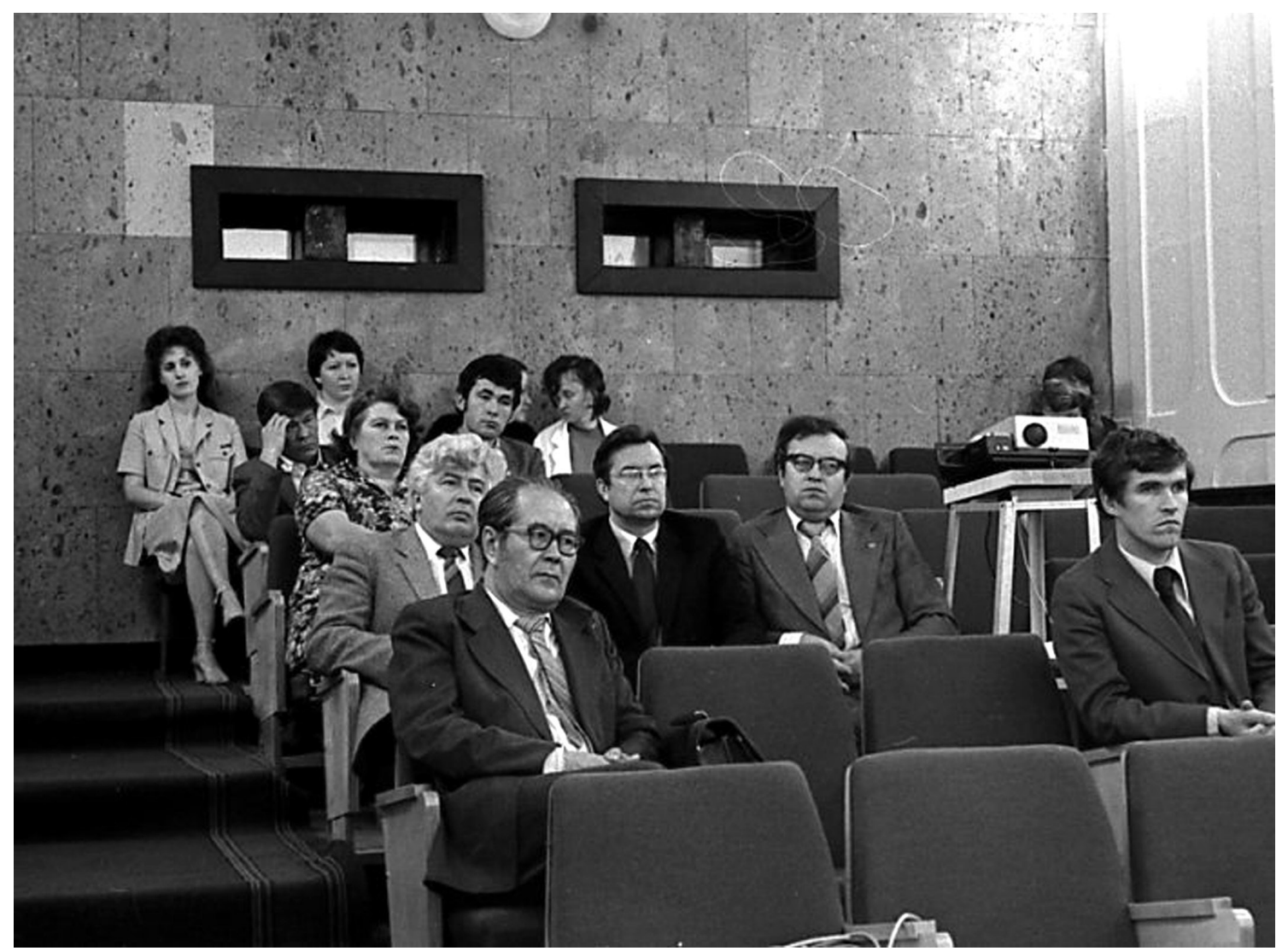

Рис. 2. В.С. Горбунов и Ю.А. Морозов (в центре), Н.Г. Рутто (справа, на заднем ряду) на заседании Ученого совета Музея археологии и этнографии. Фото из архива отдела археологических исследований ИИЯЛ УФИЦ РАН

Fig. 2 V.S. Gorbunov and Y.A. Morozov (center), N.G. Rutto (right, back row) at the meeting of the Academic Council of the Archaeology and Ethnography Museum. Photo from the archive of the Archaeological Research department of the IHLL UFRC RAS 


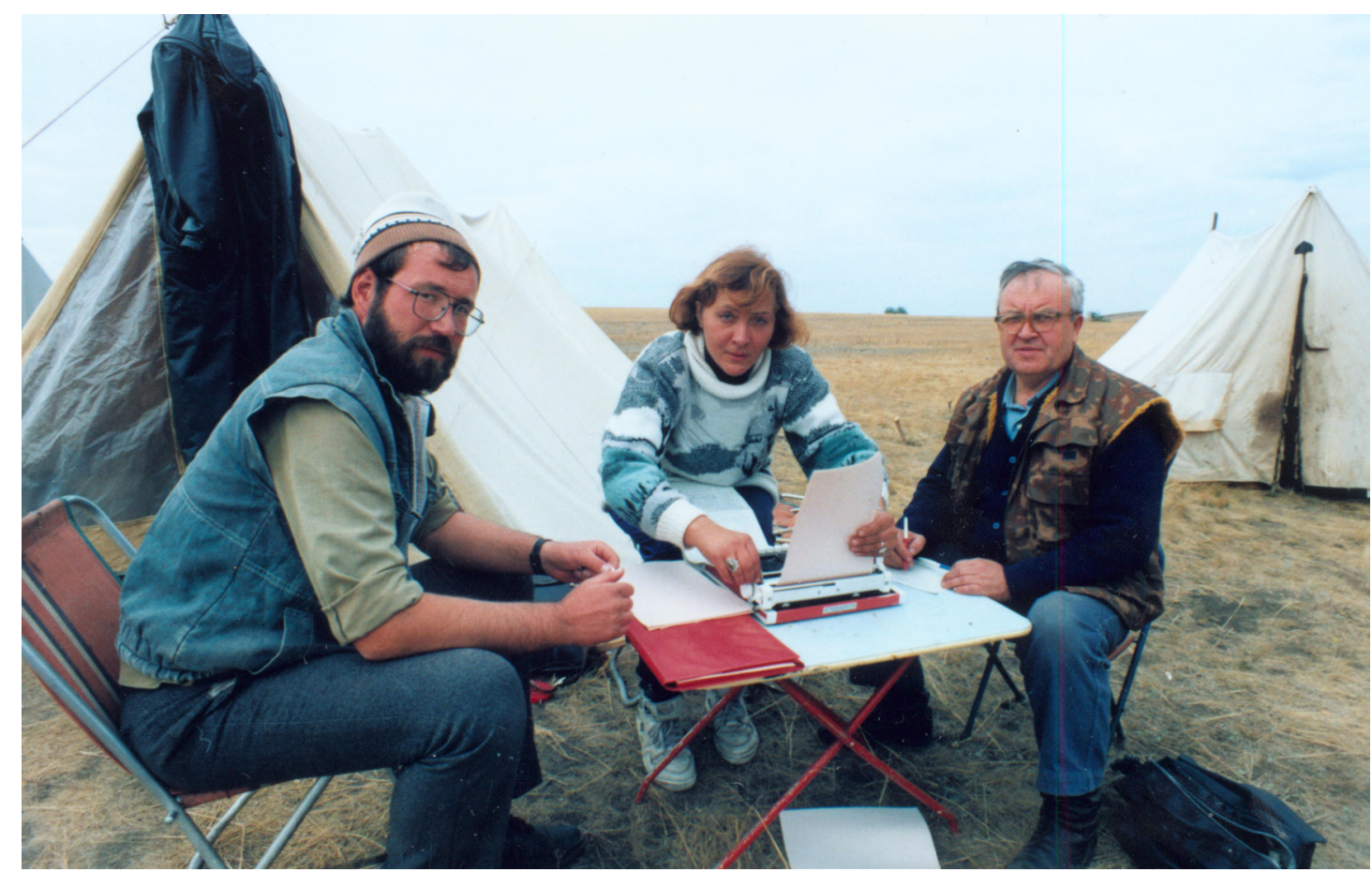

Рис. 3. В.С. Горбунов (справа) на раскопках поселения Таналык. Осень 1995 года. Фото из архива отдела археологических исследований ИИЯЛ УФИЦ РАН

Fig. 3. V.S. Gorbunov (right) at the excavations of Tanalyk settlement. Autumn 1995. Photo from the archive of the Archaeological Research department of the IHLL UFRC RAS

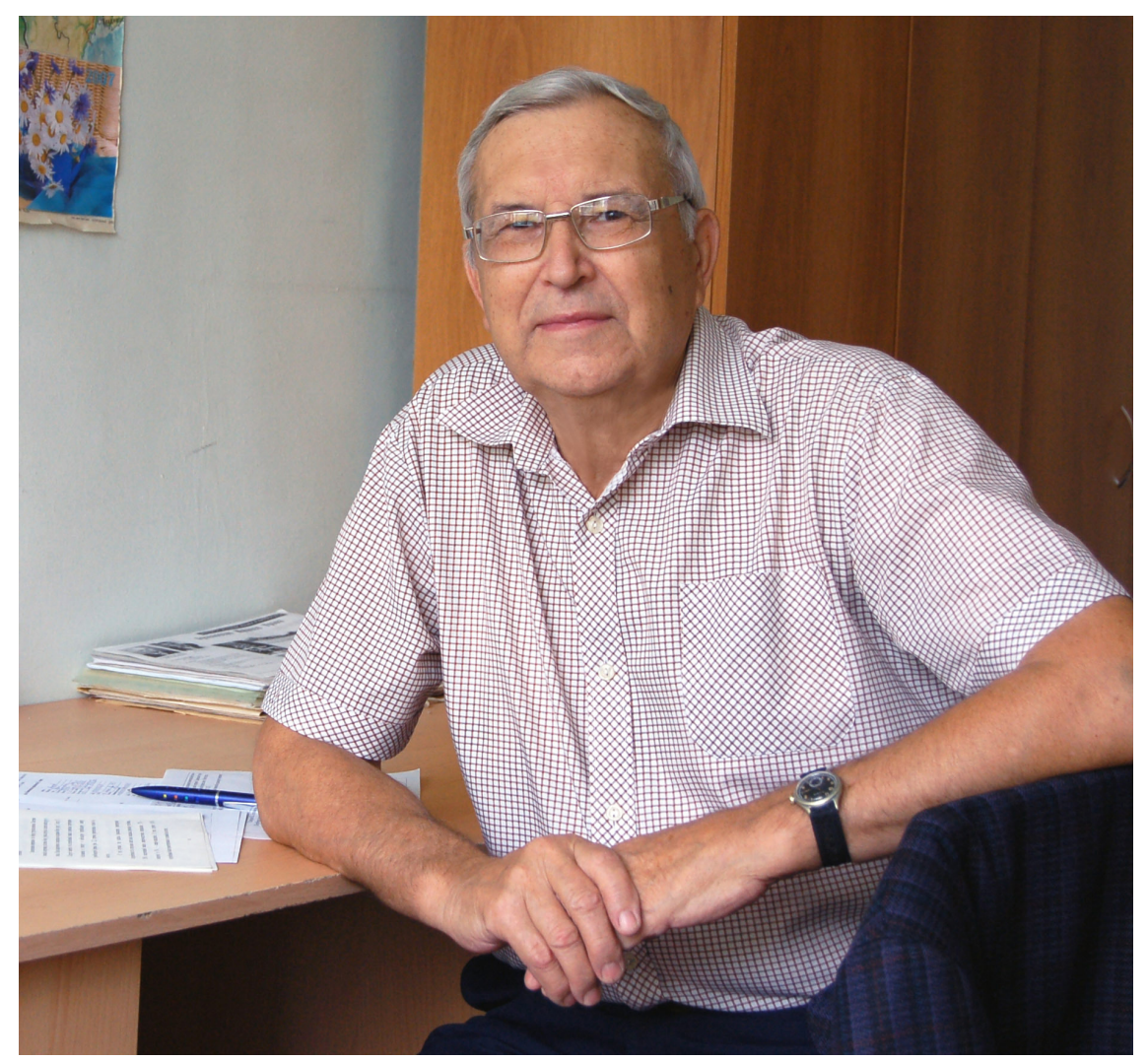

Рис. 4. Ю.А. Морозов в рабочем кабинете в Институте истории, языка и литературы. 2010 год. Фото из архива отдела археологических исследований ИИЯЛ УФИЦ РАН

Fig. 4. Yu.A. Morozov in his office at the Institute of History, Language and Literature. 2010. Photo from the archive of the Archaeological Research department of the IHLL UFRC RAS 


\section{Юрий Алексеевич Морозов}

Полевые исследования Юрия Алексеевича Морозова охватили территорию Южного Приуралья и Зауралья. На территории Приуралья им была изучена значительная серия поселенческих и погребальных памятников эпохи бронзы. Среди поселенческих памятников, раскопанных большими площадями - Чишминское, Исмагиловское, Абдулловское III, Усмановское I и II, Казангуловское, Аитовское. Некрополи эпохи бронзы, на которых им были проведены масштабные раскопки - Старо-Ябалаклинский, Чишминский и Николаевский. В Зауралье Ю.А. Морозовым исследован комплекс памятников эпохи бронзы Тавлыкаевского поселения, содержащего разнокультурные материалы, и в своей основе срубных Тавлыкаевских I и II могильников.

Основные научные интересы Ю.А. Морозова связаны с проблематикой срубной культуры. В его кандидатской диссертации «История племен срубной культуры Бельско-Уральского междуречья» были систематизированы и охарактеризованы материалы срубной культуры данной территории, и это были в основном материалы памятников, изученных автором на протяжении десятилетия полевых работ [Морозов, 1977]. Задачи, сформулированные в его диссертации, а именно - выявление локального своеобразия срубных памятников исследуемого региона, анализ материалов поселений с целью реконструкции хозяйственной деятельности, выявление направлений культурных связей, уточнение хронологии и периодизации стали магистральными и в его дальнейших исследованиях и решались на материалах памятников срубной культуры уже более широкой территории - всего южноуральского региона. Решение этих задач реализовывалось ученым в основном через публикацию памятников в статьях и книгах. Так, в монографическом исследовании материалов Аитовского поселения, характеристике хозяйства посвящена отдельная очень увлекательно написанная глава, в которой на основе анализа костяных и каменных орудий рассмотрена специфика различных производств - кожевенного, текстильного, гончарного, косторезного [Морозов, 2017. C. 142-192].

Научные интересы Ю.А. Морозова не исчерпывались только эпохой бронзы. Им был исследован ряд неолитических и энеолитических памятников: Среднеокская, Кара-Якуповская, Чишминская, Максютовская, Буртюковская, Гумеровская стоянки. На Кара-Якуповской стоянке Ю.А.Морозову удалось обнаружить редчайшие для эпохи энеолита погребения [Морозов, 1984]. Отметим, что уникальный комплекс украшений из зеленого сланца, найденный в этих погребениях, является одним из самых эффектных экспонатов в экспозиции Музея археологии и этнографии УФИЦ РАН [Музей археологии и этнографии, 2007. С.41].

Научные работы не всегда дают возможность разглядеть за ними человека. Многое становится ясно из свидетельств людей, деливших с ним тяготы и радости экспедиции. О Юрии Алексеевиче, который в течение многих лет был руководителем археологического кружка «Юнар» при Дворце пионеров, достаточно привести только одно из них: «Сложно выразить словами то восхищение, которое вызывало умение Юрия Алексеевича общаться с людьми. Как он умел легко и просто, не вдаваясь в педагогические дебри, найти правильный подход к иногда «неправильным» подросткам и к их поступкам? ... Многие годы после нашего сотрудничества я думала: «Вот бы все педагоги были такими!» [Бадри, 2011. С. 8-9].

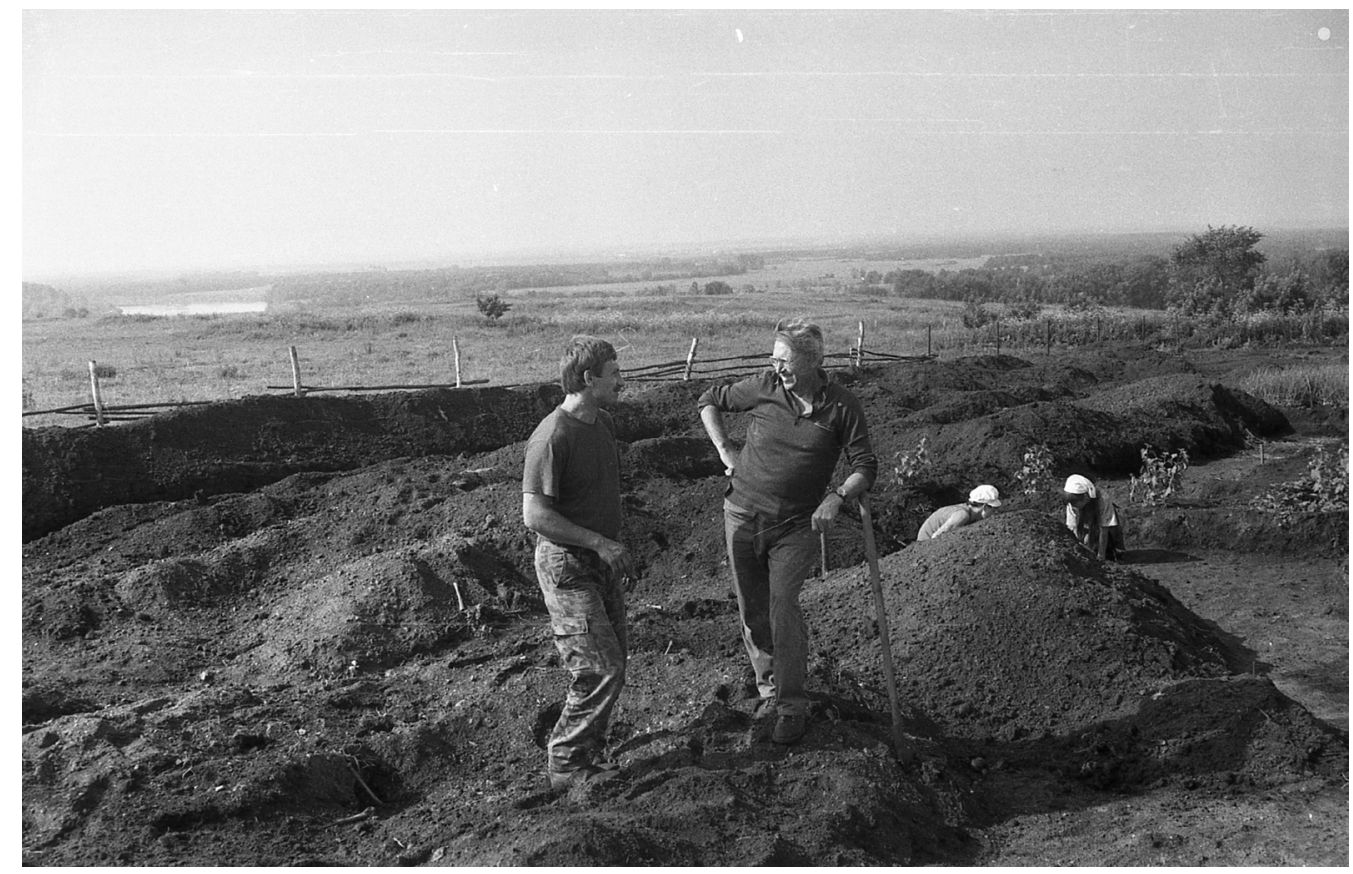

Рис. 5. Ю.А. Морозов (справа) на раскопках Шиповского могильника в Иглинском районе Башкортостана. 1993 год. Фото из архива отдела археологических исследований ИИЯЛ УФИЦ РАН

Fig. 5. Yu.A. Morozov (right) at the excavations of Shipovo necropolis in the Iglinsky district of the Republic of Bashkortostan. 1993. Photo from the archive of the Archaeological Research department of the IHLL UFRC RAS 


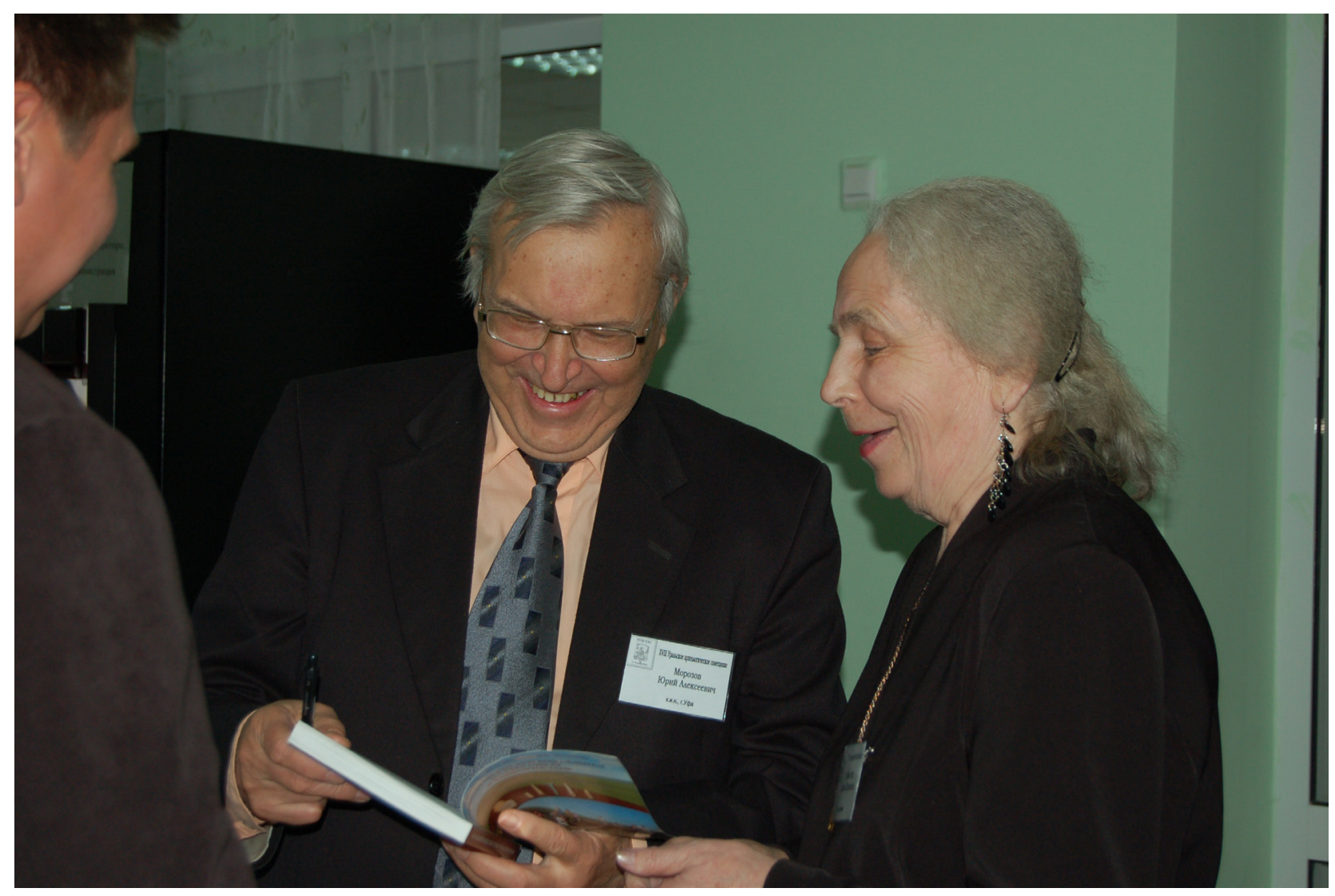

Рис. 6. Ю.А. Морозов и Е.Е. Кузьмина на Уральском археологическом совещании в Уфе. 2010 год. Фото из архива отдела археологических исследований ИИЯЛ УФИЦ РАН

Fig. 6. Yu.A. Morozov and E.E. Kuzmina at the Ural Archaeological Meeting in Ufa. 2010. Photo from the archive of the Archaeological Research department of the IHLL UFRC RAS

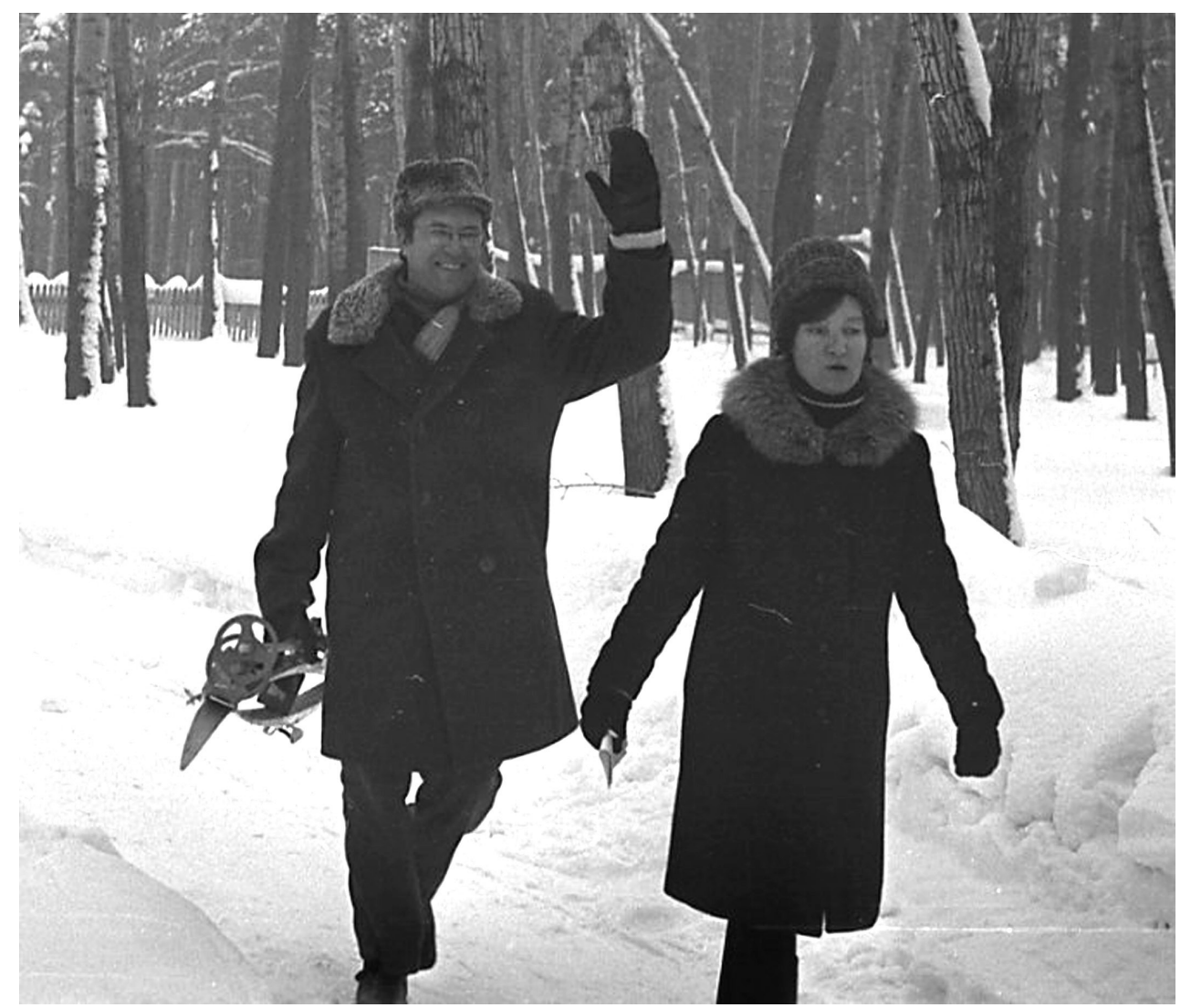

Рис. 7. Ю.А. Морозов и Н.Г. Рутто на профсоюзных соревнованиях по бегу на лыжах. Фото из архива отдела археологических исследований ИИЯЛ УФИЦ РАН

Fig. 7. Yu.A. Morozov and N.G. Rutto at the Trade Union Skiing Competition.

Photo from the archive of the Archaeological Research department of the IHLL UFRC RAS 


\section{Наталья Георгиевна Рутто}

Натальи Георгиевны Рутто нет среди нас вот уже более 14 лет. Ее научные интересы были связаны с одной очень сложной и многогранной темой - проблемой связей двух культурно-исторических общностей - срубной и алакульской, свидетельством чего являлись смешанные памятники, исследованные на территории Южного Урала. Исследователь поступательно шла к раскрытию этой темы.

Ею в научный оборот была введена значительная часть материалов курганов бронзовой эпохи, раскопанных исследователями, в область научных интересов которых они не входили. Это материалы Ново-Мурапталовских, Биккуловских, Ивановских I, II, IV, Мамбетовских II, VII, Сибайских II, Альмухаметовских II, Булатовских и Казанкинских курганов. Эти публикации отличает тщательность подготовки материала, скрупулезность его анализа, а также обоснованность и взвешенность выводов [Рутто, 1982; 1995].

Результатом многолетних исследований Н.Г. Рутто явилась кандидатская диссертация, которая в последующем была издана в виде монографии «Срубно-алакульские связи на Южном Урале» [Рутто, 2003]. Она стала первой обобщающей работой по этой теме с тех пор, как К.В.Сальников обозначил наличие проблемы срубно-алкульских контактов [Сальников, 1950]. В ней Натальей Георгиевной проанализированы материалы 30 поселений и 78 могильников с проявлениями срубноалакульского синкретизма и сделан ряд важных выводов. Было выяснено, что зонами наиболее активных контактов являлось Урало-Сакмарское междуречье, а также территория Западного Оренбуржья. Начало их определено раннесрубным и раннеалакульским временем. В качестве наиболее вероятного механизма названы межродовые экзогамные браки, «предполагавшие инкорпорирование женщин срубной культуры в алакульскую среду, а женщин алакульской культуры - в срубную». Сама Наталья Георгиевна отмечала, что «в работе дан анализ лишь некоторых вопросов взаимосвязей крупных культурно-исторических общностей». Надо сказать, что проблема срубноалакульских взаимодействий остается чрезвычайно актуальной. Вновь выявленные срубные и срубно-алакульские памятники, расположенные восточнее пределов очерченной Н.Г. Рутто территории, ставят перед исследователями новые задачи, но работа Натальи Георгиевны всегда будет

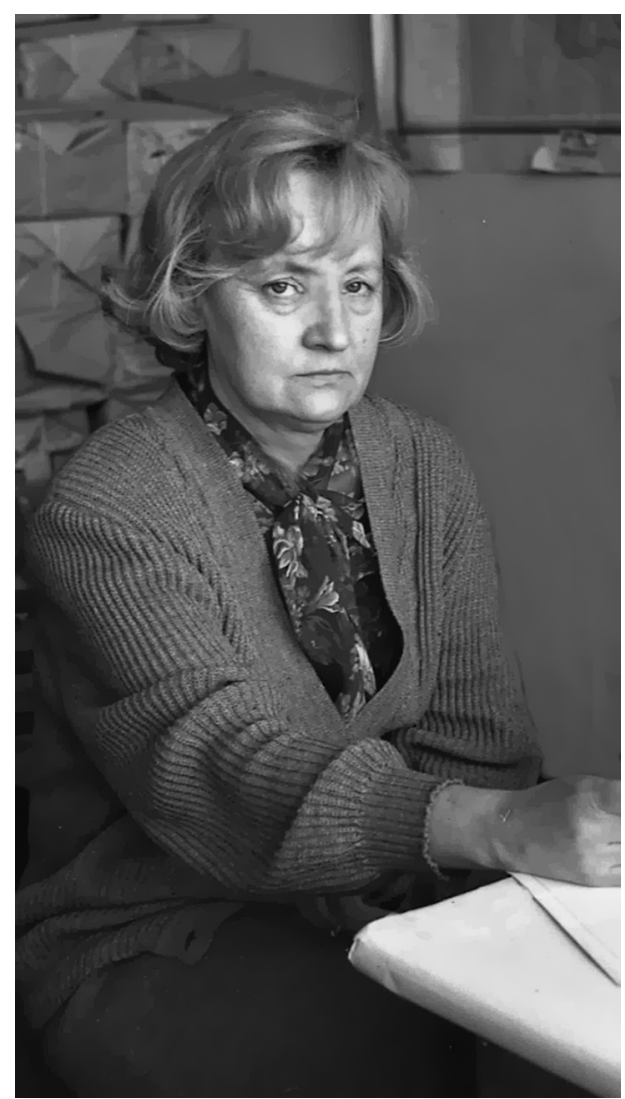

Рис. 8. Н.Г. Рутто на рабочем месте в Музее археологии и этнографии. Фото из архива отдела археологических исследований ИИЯЛ УФИЦ РАН

Fig. 8. N.G. Rutto at his workplace in the Archaeology and Ethnography Museum. Photo from the archive of the Archaeological Research department of the IHLL UFRC RAS

являться фундаментом для любых дальнейших исследований этой сложной проблемы. Н.Г.Рутто являлась бессменным хранителем фондов Музея археологии и этнографии на протяжении 28 лет, и благодаря именно ей коллекции находились в идеальном порядке.

\section{Заключение}

В работах В.С.Горбунова, Ю.А.Морозова и Н.Г.Рутто была развита и значительно дополнена концепция К.В.Сальникова. Многократно расширена база археологических источников. Найдены ответы на большинство поставленных перед ними наукой вопросов и многие проблемы эпохи бронзы Южного Урала были ими решены. Их работы являются основополагающим фундаментом для последующих поколений исследователей эпохи бронзы Южного Урала.

\section{СПИСОК ЛИТЕРАТУРЫ}

БадриГ.В. Путешествие во времени // Юрий Алексеевич Морозов. Биобиблиографический указатель. К 70-летию со дня рождения / Отв. ред. В.В.Овсянников. Уфа: ИИЯЛ УНЦ РАН, 2011. C. 7-9.

Горбунов В.С. История племен абашевской культуры в бассейне р.Белой. Автореф. дисс. ... канд. ист. наук. М., 1977. 25 с.

Горбунов В.С. Курганы эпохи бронзы на пра- вобережье р. Демы (Башкирия) // Советская археология. 1977б. № 1. С. 149-161.

Горбунов В.С. Абашевская культура Южного Приуралья: Учеб. пособие к спецкурсу. Уфа: БГПИ, 1986. $96 \mathrm{c}$.

Горбунов В.С. Поселенческие памятники бронзового века в лесостепном Приуралье: Учеб. пособие по спецкурсу. Куйбышев: КГПИ, 1989. $136 \mathrm{c}$. 
Горбунов В.С. Бронзовый век Волго-Уральской лесостепи. Уфа: БГПИ, 1992. 224 с.

Морозов Ю.А. История племен срубной культуры Бельско-Уральского междуречья. Автореф. дисс. ... канд. ист. наук. М., 1977. 10 с.

МорозовЮ.А. Кара-Якуповская энеолитическая стоянка // Эпоха меди юга Восточной Европы / Отв. ред. Н.Я. Мерперт. Куйбышев: КГПИ, 1984. C. $43-58$.

МорозовЮ.А. Аитовское поселение эпохи бронзы в Башкирском Приуралье. Уфа: УНЦ РАН, 2017. 232 c.

Музей археологии и этнографии: Каталог музейной экспозиции Центра этнологических исследований Уфимского научного центра РАН / Отв. ред. А.Б. Юнусова. Уфа: ЦЭИ УНЦ РАН; Информреклама, 2007. $220 \mathrm{c}$.
Рутто Н.Г. Новые срубно-алакульские памятники Южного Приуралья // Приуралье в эпоху бронзы и раннего железа / Под ред. В.А. Иванова, А.Х.Пшеничнюка. Уфа: БФАН СССР, 1982. C. 20-29.

Рутто Н.Г. Курганы эпохи бронзы на юго-востоке Башкирии // Наследие веков. Охрана и изучение памятников археологии в Башкортостане. Вып. 1 / Отв. ред. М.Ф.Обыденнов. Уфа: НМРБ, 1995. C. 41-57.

Рутто Н.Г. Срубно-алакульские связи на Южном Урале. Уфа: Гилем, 2003. 212 с.

Сальников К.В. Хвалынско-андроновские курганы у с.Погромного // Советская археология. Вып. XIII. 1950. C. 311-319.

Сальников К.В. Очерки древней истории Южного Урала. М.: Наука, 1967. 408 с.

\section{REFERENCES}

Badri, G.V. "Time travel", Yurij Alekseevich Morozov. Biobibliograficheskij ukazatel'. K 70-letiyu so dnya rozhdeniya ("Yuri Alexseevich Morozov. Bibliographic index. To the $70^{\text {th }}$ anniversary"). Ufa, 2011, pp. 7-9. (In Russ.)

Gorbunov, V.S. 1977, "History of the Abashevo culture tribes in the basin of the Belaya river. Dissertation abstract ... Candidate of Historical Sciences". Moscow, 25 p. (In Russ.)

Gorbunov, V.S. 1977, "The Bronze Age barrows on the right bank of the Dema river (Bashkiria)", Sovetskaya Archeologiya, no.1, pp.149-161. (In Russ.)

Gorbunov, V.S. 1986, "The Abashevo culture of the Southern Cis-Urals: A student's handbook to the academic minor". BGPI, Ufa, 96p. (In Russ.)

Gorbunov, V.S. 1989, "The Bronze Age archaeological settlements of the forest-steppe Cis-Urals: A student's handbook to the academic minor". KGPI, Kujbyshev, 136 p. (In Russ.)

Gorbunov, V.S. 1992, "The Volga-Ural foreststeppe in the Bronze Age”. BGPI, Ufa, 224p. (In Russ.)

Morozov,Y.A. 1977, "History of the Srubnaya culture tribes in the Belaya-Ural interfluve region. Dissertation abstract ... Candidate of Historical Sciences". Moscow, 10p. (In Russ.)

Morozov, Y.A. "The Chalcolithic site of the KaraYakupovo culture", Epoha medi yuga Vostochnoj Evropy ("The Copper Age in the South region of Eastern Europe"). Kujbyshev, 1984, pp. 43-58. (In Russ.)
Morozov, Y.A. 2017, "The Bronze Age settlement of Aitovo in the Bashkir Cis-Urals region". UNC RAN, Ufa, 232 p. (In Russ.)

Muzej arheologii i etnografii: Katalog muzejnoj ekspozicii Centra etnologicheskih issledovanij Ufimskogo nauchnogo centra RAN ("Museum of Archaeology and Ethnography: Collection catalogue of the Center of Ethnological studies of the Ufa Scientific Center of the RAS"). Ufa, 2007, 220 p. (In Russ.)

Rutto, N.G. "New sites of the Srubnaya and the Alakul cultures in the Southern Cis-Urals", Priural'e $v$ epohu bronzy i rannego zheleza ("Cis-Urals region in the Bronze and Early Iron Age"). Ufa, 1982, pp. 20 29. (In Russ.)

Rutto, N.G. "The Bronze Age barrows in the South-East of Bashkiria", Nasledie vekov. Ohrana $i$ izuchenie pamyatnikov arheologii v Bashkortostane. Vyp. 1, ("Heritage of the centuries. Protection and study of archaeological sites in the Republic of Bashkortostan, vol. 1"). Ufa, 1995, pp.41-57. (In Russ.)

Rutto, N.G. 2003, "Interactions between the Srubnaya and the Alakul cultures in the Southern Urals region”. Gilem, Ufa, 212 p. (In Russ.)

Salnikov, K.V. 1950, "Barrows of the Khvalynsk and Andronovo cultures near Pogromnoye village", Sovetskaya Archeologiya, vol.13, pp.311-319. (In Russ.)

Salnikov, K.V. 1967, "Essays on the ancient history of the Southern Urals region”. Nauka, Moscow, 408 p. (In Russ.)

\section{Сведения об авторе}

Янина Валерьевна Рафикова, кандидат исторических наук, старший научный сотрудник, Институт истории, языка и литературы, Уфимский федеральный исследовательский центр РАН, Российская Федерация, г. Уфа. E-mail: ziada@bk.ru, ORCID: 0000-0002-2393-9366

\section{Information About the Author}

Yanina V. Rafikova, Ph.D., senior researcher, Institute of History, Language and Literature, Ufa Federal Research Center of the RAS, Russian Federation, Ufa. E-mail: ziada@bk.ru, ORCID: 0000-0002-2393-9366 